\title{
A Dual-Bridge Hybrid DC Circuit Breaker
}

\author{
Hanwen Zhang \\ AAU Eenergy \\ Aalborg University \\ Aalborg, Denmark \\ hzha@et.aau.dk
}

\author{
Gen Li \\ School of Engineering \\ Cardiff University \\ Cardiff, UK \\ LiG9@cardiff.ac.uk
}

\author{
Yanbo Wang \\ AAU Eenergy \\ Aalborg University \\ Aalborg, Denmark \\ ywa@et.aau.dk
}

\author{
Chuang Liu \\ School of Electrical Engineering \\ Northeast Electric Power \\ University \\ Jilin, China \\ victorliuchuang@163.com
}

\author{
Zhe Chen \\ AAU Eenergy \\ Aalborg University \\ Aalborg, Denmark \\ zch@et.aau.dk
}

\begin{abstract}
Various DC circuit breakers (DCCBs) have been widely proposed for the $\mathrm{DC}$ fault protection of high-voltage directcurrent (HVDC) grids. In recent years, hybrid DCCBs (HCBs) have been paid significant attentions due to their features of low power losses and fast dynamic response. However, several aspects regarding the design of $\mathrm{HCB}$ should be further addressed. For instance, the requirement of deploying a large surge arrester to dissipate the large fault current energy should be further addressed and the strategy to perform zero-voltage switching (ZVS) of semiconductor devices during the post-fault restoration processes should be investigated. In this paper, a dual-bridge hybrid DC circuit breaker (DB-HCB) with freewheeling diode branches is proposed to address the above issues. The operation principle of the proposed DB-HCB for pole-to-ground and poleto-pole faults is presented. Compared with other HCBs, the capacity of the surge arrester is obviously reduced, so that the capital cost and volume of the proposed DB-HCB is decreased. Moreover, the ZVS is implemented during the post-fault restoration processes. Simulation results in PSCAD/EMTDC are given to validate the effectiveness of the proposed DB-HCB.
\end{abstract}

Keywords-DC circuit breaker, DC protection, DC fault current, DC grid, HVDC, MTDC, fault protection, surge arrester.

\section{INTRODUCTION}

Renewable energy sources (RES), such as wind power and solar power, etc. are playing significant roles in achieving sustainable and low-carbon development [1]-[3]. Due to the remote geographical location of large-scale RES, high-voltage direct-current (HVDC) transmission system has been widely utilized for renewable energy integration [4]-[5]. Nowadays, the voltage source converter (VSC)-based HVDC technology has been increasingly adopted in HVDC transmission system compared with the line-commutated-converter-(LCC) based HVDC system [6]-[9].

DC circuit breaker (DCCB) is one of critical components in VSC-HVDC systems, which is able to provide a fast and reliable DC fault protection for multi-terminal HVDC (MTDC) grids [10]-[12]. The interruption of DC fault current is difficult due to the lack of the natural current zero-crossing and its high rising-rate [13]. Therefore, the DCCBs have been paid the increasing concerns from academia and industry.
DCCBs consist of mechanical circuit breakers (MCBs), solid-state circuit breakers (SSCBs) as well as hybrid circuit breakers (HCBs) [14]. MCB has low on-state losses and high reliability. However, the fault current interruption time of the MCB can be delayed to tens milliseconds or longer due to longterm operation of mechanical switch, which reduces the safety for MTDC grid protection [15]. In SSCBs, power electronic devices are adopted to improve the current interruption speed [16]. However, the on-state power losses of SSCBs are high due to the internal resistance of power electronic devices. Moreover, cooling systems for the normal operating branch are required, which also increases the system complexity and volume [10]. Compared with the MCB and SSCB, HCB combines the advantages of the two solutions. The HCB exhibits the fast interrupting speed as well as the low on-state power losses [17][19]. However, the high capital cost and large volume commonly limit the practical application of HCBs in MTDC systems.

In recent years, the intensive research regarding $\mathrm{HCB}$ has been performed. The HCB is originally proposed for HVDC application by ABB company in 2012, which uses front-to-front connected insulated gate bipolar transistors (IGBTs) in the load commutation switch (LCS) and main breaker (MB) to achieve bidirectional operation [10], [20]. In normal condition, the load current flows through the branch of the ultra-fast disconnector (UFD) and the LCS, which exhibits the merit of the low power losses. In fault condition, the fault current will be commutated to the MB under the arc voltage by turning off the LCS. The UFD can be opened under zero current once the current in this branch fully commutates to the MB. Then, the fault current will be forced to the surge arrester by blocking the MB, so that the energy will be dissipated.

The deployment of the IGBT-based MB implements the excellent current breaking capability and arc extinction capacity. Therefore, the interruption speed of DCCB is significantly improved. However, the VSCs are always connect to the fault point during the fault current interrupting and energy dissipating processes. Therefore, it fails to isolate the converter from the faulted line until the fault current completely diminished. Additionally, the surge arrester needs to absorb a large amount 
of fault current energy within a short period which may lead to overheating and a large reverse-voltage. Therefore, the requirements for the capacity of the surge arrester and the insulation of the DCCB will be high. Another issue of the HCB is that the IGBTs fail to achieve the zero voltage switching (ZVS) during the post-fault restoration process. Further, it is difficult to perform the dynamic voltage balancing of IGBTs [21].

A full-bridge submodule (FB-SM)-based HCB is proposed and applied in Zhoushan five-terminal VSC-HVDC project [22]-[23]. Due to the employment of the SM capacitor, the issue of the dynamic voltage balancing of the IGBT modules in the above HCB has been addressed. It can be seen that a number of semiconductor devices and capacitors are required, so that the capital cost and power losses are increased.

In order to reduce the number of IGBTs, a diode FB-SM based HCB is proposed and applied in the Zhangbei $500 \mathrm{kV}$ four-terminal DC grid project [24]. The capital cost is reduced compared with the circuit used in Zhoushan project. However, the stray inductance of the series-connected diodes may prolong the current conduction time. Hence, the magnitude of the interruption current is higher than the above topologies. In [25], a thyristor-capacitor-based HCB is proposed to mitigate the use of IGBT, which needs the parallel auxiliary branch to limit fault current. In this case, the magnitude of the interrupted fault current can be increased.

The surge arresters of the abovementioned DCCBs are required to absorb energy of fault current. In [26], a surgearrester-less SSCB is proposed to address the above issues. However, this surge-arrester-less SSCB has the evident drawbacks such as unidirectional current interrupting and high on-state power losses.

To address the above issues, this paper presents a dualbridge HCB (DB-HCB) with the additional freewheeling diode branches, which is able to reduce the capacity and volume of the surge arrester as well as maintain the energy dissipating capability. The strategy of the fault current interruption and the post-fault restoration is developed for both pole-to-ground and pole-to-pole faults. The fault interruption process consists of two stages, including the current commuting stage and the energy dissipating stage. The proposed DB-HCB can rapidly isolate the VSCs from the faulted circuit after the current commuting stage. The fault current energy will then be gradually dissipated by the surge arresters in the freewheeling diode branches. Moreover, the ZVS can be implemented in the post-fault restoration process, which improves the safety and the lifetime of the DBHCB. The effectiveness of the proposed DB-HCB is verified by time-domain simulations in PSCAD/EMTDC.

\section{Topology of The Proposed DB-HCB}

Fig. 1 shows the circuit configuration of the proposed DB$\mathrm{HCB}$. It can be seen that the terminal $\mathrm{A}$ and $\mathrm{C}$ are connected to DC source and DC transmission line, respectively. Terminal B is connected to the ground. The DB-HCB consists of dual symmetrical bridges, where each bridge consists of four parts. a) Disconnector. The disconnector is a UFD which is able to isolate the converter from the faulted circuit when the fault current is interrupted.

b) Normal current carrying branch (NCCB). The NCCB consists of a UFD and an IGBT-based bidirectional LCS, which provides the path for normal current in steady-state.

c) Fault current breaking branch - main breaker (MB). The MB consists of a number of unidirectional series-connected IGBT modules. The IGBTs in two MBs form a front-to-front connection. The circuit with a capacitor $C_{Q}$ and a resistor $R_{Q}$ is deployed in paralleled with each IGBT module.

d) Energy dissipating branch (EDB). In the EDB, the freewheeling diodes are connected in series with a surge arrester. Snubber resistor $R_{D}$ is paralleled with each diode.

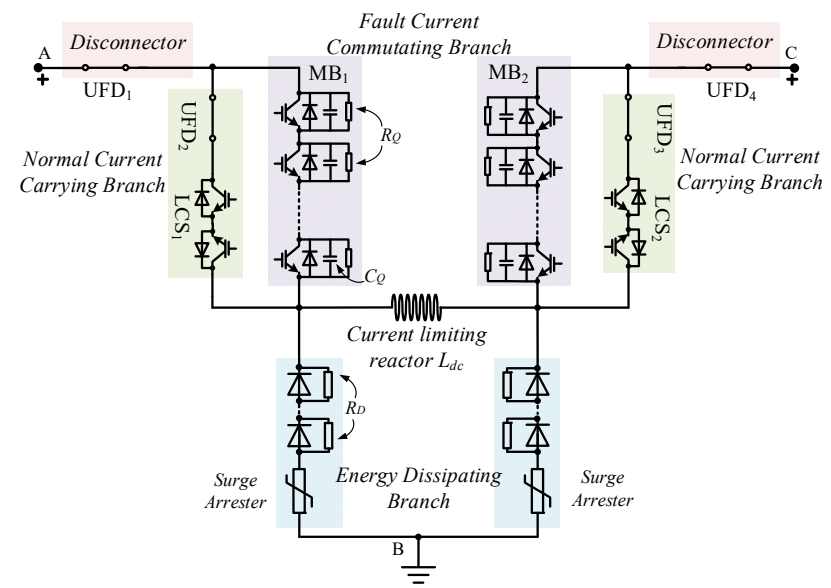

Fig. 1. The circuit configuration of the proposed DB-HCB.

\section{OPERATING PRINCIPLE OF THE DB-HCB}

\section{A. Fault current interruption}

It is assumed that the terminal $\mathrm{A}$ is connected to a converter and the terminal $\mathrm{C}$ is connected to the DC line, and a DC fault occurs in the DC line. The fault current interrupting principles of the proposed DB-HCB are illustrated in Fig. 2 and explained as follows.

1) The normal current $i_{N}$ passes through the two NCCBs and the current limiting reactor $L$ during normal operation, as shown in Fig. 2(a). The two MBs are operated in the off-state.

2) The current $i_{F}$ will start to increase in case of a DC line fault. The current path of the fault current $i_{F}$ is shown in Fig. 2(b) before it reaches the specified protection threshold.

3) The LCSs in the two NCCBs will be terminated once the magnitude of $i_{F}$ reaches the specified thresholds. In order to speed up the current commutation process, the IGBTs in $\mathrm{MB}_{1}$ and $\mathrm{MB}_{2}$ can be triggered earlier before blocking the LCS. The fault current will commutate to the MBs.. Fig. 2(c) shows the fault current path at this stage. 
4) The UFDs in the two NCCBs will be opened at zero current once the fault current fully commutates to the MBs. This process may take 1 to $2 \mathrm{~ms}$. Then, MBs can be blocked and $i_{F}$ will charge the capacitor $C_{Q}$ in $\mathrm{MB}_{1}$. The voltage of each mode in $\mathrm{MB}_{1}$ can be balanced due to the capacitor $C_{Q}$. Fig. 2(d) shows the fault current path at this stage.

5) The fault current $i_{F}$ will reach the maximum value once the voltage of $C_{Q}$ in $\mathrm{MB}_{1}$ is equal to the voltage of terminal A. Then, the freewheeling diodes in EDB provide the path for the residual fault current so as to dissipate the energy stored in the current limiting reactor. At this moment, the converter has been isolated from the faulted circuit by opening the UFD 1 under zero current. In this way, the converter is safely isolated from the faulted circuit. Then, the fault current is dissipated through the surge arrester and the freewheeling diodes in the EDB and $\mathrm{MB}_{2}$. The fault current path at this stage is shown in Fig. 2(e). Then, the residual current will decay to zero.

6) The $\mathrm{UFD}_{4}$ is activated when the residual current decay to zero. Then, the fault circuit is fully isolated. The energy stored in the $C_{Q}$ is fully dissipated by $R_{Q}$ over a certain time period. The last stage is shown in Fig.2(f).
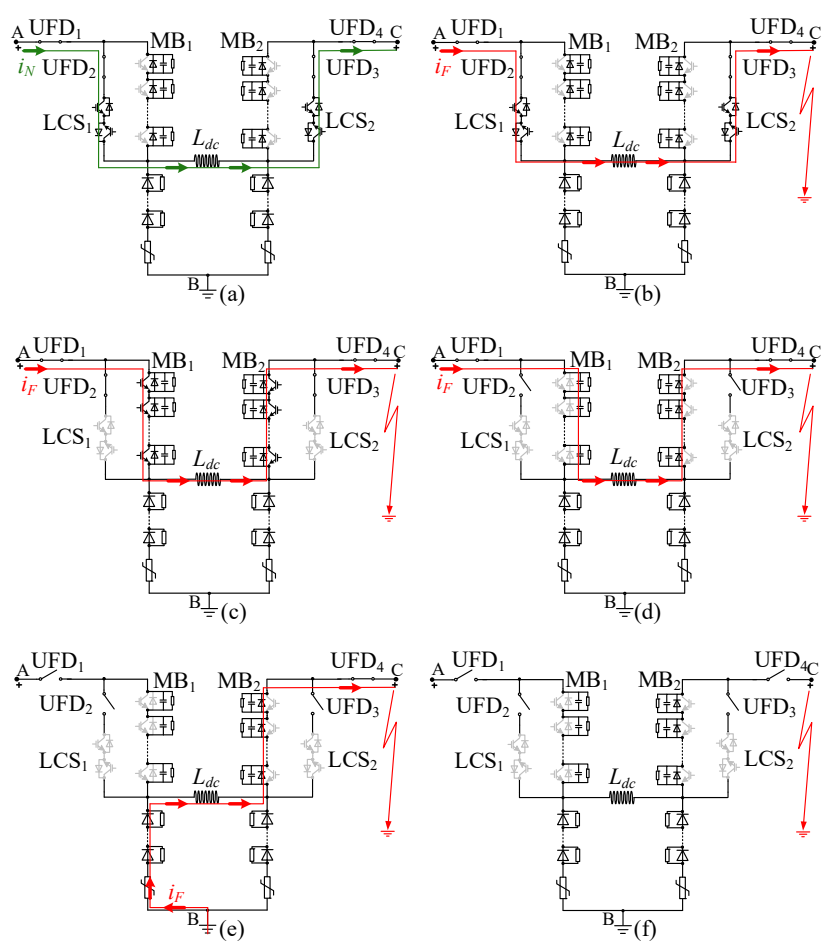

Fig. 2. Fault current interrupting processes of the proposed DB-HCB.

\section{B. Fault current interruption Post Fault Restoration}

After the fault current is interrupted, there exists a deionization period to extinguish the residual arc, and the faulted line is under low voltage. The following steps will be executed once the DB-HCB receives a reclosing order from the high-level control system.
1) The first step is to close the UFD 1 and $\mathrm{UFD}_{4}$.

2) Turn on the IGBTs in the two MBs once the UFD ${ }_{1}$ and $\mathrm{UFD}_{4}$ are fully closed.

3) After the above operations, the load current flows through the DB-HCB and charge the DC line naturally.

4) Close the $\mathrm{UFD}_{2}$ and $\mathrm{UFD}_{3}$, and turn on the $\mathrm{LCS}_{1}$ and $\mathrm{LCS}_{2}$ in the two NCCBs. Then, the current will commutate to the two NCCBs.

5) Turn off the IGBTs in the two MBs. The switching process of the IGBTs implement the ZVS.

\section{DesGin OF THE SURGE ARRESTER}

Compared with other HCBs, one of the advantages of proposed DB-HCB is reduced capacity of the MB surge arrester, so that the volume and capital cost is reduced. A comparative analysis between the proposed DB-HCB and the ABB HCB is given in Table I.

TABLE I

THE COMPARISON OF THE ABB HCB AND THE PROPOSED DB-HCB

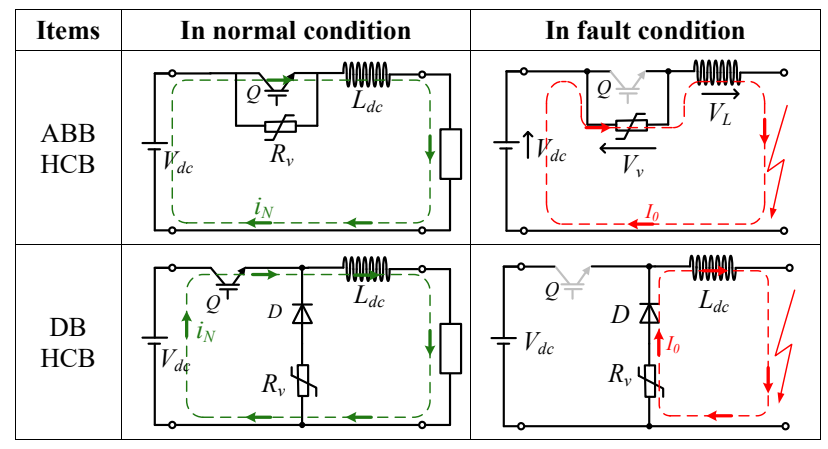

Table I shows the equivalent circuits and operation principles of the ABB HCB and the proposed DB-HCB. The voltage source $V_{d c}$ supplies the resistive load. The inductor $L_{d c}$ represents the overall inductance of the DCCB and DC transmission line. $Q$ is a solid-state power switch that represents the IGBTs in the MB. $R_{v}$ represents the variable resistance of the surge arrester.

\section{A. $A B B H C B$}

In normal condition, the load current $i_{N}$ flows to the load through $Q . Q$ will be turned off immediately if a fault is detected. It is assumed that $I_{0}$ is the instantaneous current at the moment of turning off $Q$, and it will be commutated to $R_{v}$. The voltage stress of $Q$ equals the clamping voltage of $R_{v}$. It is assumed that the clamping voltage of the arrester is $V_{v}$. Then, it can be presented as (1)

$$
V_{v}=V_{d c}+V_{L}
$$

where $V_{L}$ is the voltage of $L_{d c}$ when $Q$ is turned off $(t=0)$. Therefore, the current in $L_{d c}$ can be represented as (2). 


$$
i_{L}(t)=I_{0}-\frac{V_{L}}{L_{d c}} t .
$$

Then, the fault energy is dissipated by the arrester, and the fault current is decreased to zero gradually. The time that the current $i_{L}$ is decreased to zero can be represented as (3).

$$
T_{\text {open }}=\frac{L_{d c}}{V_{L}} I_{0}
$$

The fault energy $W_{R}$ absorbed by the arrester during the energy dissipating period until time instant $T_{\text {open }}$ can be represented as (4).

$$
W_{R}=\int_{0}^{T_{\text {open }}}\left(V_{d c}+V_{L}\right) i_{R} d t
$$

where $i_{R}$ is the current flowing by $R_{v}$. and the $i_{R}$ is equal to $i_{L}$ during the energy dissipating period. Then, the following equation can be obtained as (5) by combining (1)-(4).

$$
W_{R}=\left(\frac{V_{d c}}{V_{L}}+1\right) \frac{1}{2} L_{d c} I_{0}^{2}
$$

The $V_{L}$ is much lower than $V_{d c}$ at the moment of turning off $Q$. Thus, the energy $W_{R}$ absorbed by the arrester is much higher than the energy stored $\left(L_{d c} I_{0}^{2} / 2\right)$ in $L_{d c}$ at $t=0$. In design of the surge arrestor, the high energy can be dissipated quickly without causing overheating and overvoltage. Moreover, the DC source is still in fault current path during the de-energizing process.

\section{B. $D B-H C B$}

The design guideline of the proposed DB-HCB is explained by the equivalent model as shown in Table I. During steady-state operation, the load current $i_{N}$ flows through the switch $Q$ to the load. $Q$ is switched off once the value of the fault current reaches the specified threshold. Then, the fault current will commutate to the diode $D$ and the nonlinear resistor $R_{V}$. Meanwhile, the DC source is isolated from the faulted circuit.

The residual energy stored in $L_{d c}$ is exhausted by $R_{v}$. The energy absorbed by $R_{V}$ can be calculated as (6).

$$
W_{R}=\frac{1}{2} L_{d c} I_{0}^{2} .
$$

It can be seen from (5)-(6) that WR of the proposed DB-HCB is lower than ABB's HCB. Therefore, the capacity and volume of the surge arrester can be dramatically reduced, which is an evident advantage for the proposed DB-HCB. Moreover, the front-to-front connected IGBTs in the MB of ABB's HCB are equally deployed in the two bridges (MBs) of the proposed DB$\mathrm{HCB}$. Therefore, the proposed DB-HCB has the same number of IGBTs in the MB compared with ABB's HCB. Also, the MBs in the proposed DB-HCB can be replaced by different MBs with preserving the advantages of the proposed topology.

\section{Simulation Verification}

To validate the effectiveness of fault current interruption and post-fault restoration capability of the proposed DB-HCB, a model of the proposed DB-HCB with $650 \mathrm{MW}$ and $\pm 320 \mathrm{kV}$ is developed in PSCAD/EMTDC, where both pole-to-ground and pole-to-pole faults are tested. The parameters for the simulation case are given in Table II.
TABLE II

CIRCUIT PARAMETERS IN SIMULATION CASE

\begin{tabular}{|c|c|}
\hline Items & Values \\
\hline Power rating & $640 \mathrm{MW}$ \\
\hline Nominal DC line voltage & $320 \mathrm{kV}$ \\
\hline Load impendence & $160 \Omega$ \\
\hline Number of each main breaker IGBTs & 120 \\
\hline Nominal voltage of $R_{V}$ & $20 \mathrm{kV}$ \\
\hline Current limiting reactor $L_{d c}$ & $100 \mathrm{mH}$ \\
\hline$R_{D}$ & $470 \mathrm{k} \Omega$ \\
\hline$R_{Q}$ & $1 \mathrm{k} \Omega$ \\
\hline$C_{Q}$ & $4 \mu \mathrm{F}$ \\
\hline
\end{tabular}

\section{A. Pole-to-ground fault}

Fig. 3 shows the test circuit of a pole-to-ground fault. The system rated load current $i_{N}$ is $2 \mathrm{kA}$. The mechanical breaker $\mathrm{S}_{\text {fault }}$ is placed to produce the short-circuit. The opening time of UFDs $\left(S_{1}\right.$ and $\left.S_{2}\right)$ is set as $2 \mathrm{~ms}$ with the consideration of practical condition. The UFD can only switch under zero current. IGBTs $\left(\mathrm{T}_{2}\right)$ in the MBs are in off-state during the normal operation. The specified protection threshold of the LCS $\left(T_{1}\right)$ is 2 times of the rated load current.

For the post-fault reclosing of the DB-HCB, it is assumed that the fault detection and discrimination have been successfully conducted by the protection system. The proposed $\mathrm{DB}-\mathrm{HCB}$ is reclosed when the fault is fully cleared and the fault energy is safely dissipated.

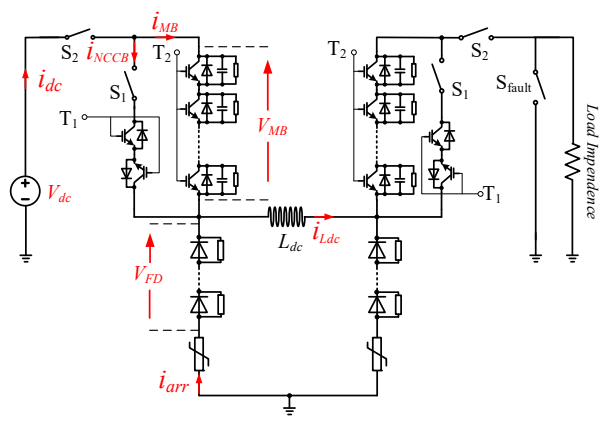

Fig. 3. The simulation circuit of the proposed DB-HCB.

In normal condition, the load current flows through NCCBs and $L_{d c}$. During this period, it can be seen from Fig. 4 that $i_{N C C B}$ equals to $i_{d c}$ whose value is $2 \mathrm{kA}$. The pole-to-ground fault happens at the time of $0.01 \mathrm{~s}$ by closing the $\mathrm{S}_{\text {fault. }}$ It shows that $i_{d c}$ starts to increase at $t=0.01 \mathrm{~s}$.

As mentioned above, the turn-off signal of $T_{1}$ is $4 \mathrm{kA}$. To prevent the failure of fault current commutation, $T_{2}$ will turn on in advance at the time when $i_{N C C B}$ equals to $3 \mathrm{kA}$. The fault current reaches to $4 \mathrm{kA}$ at the time of $0.0106 \mathrm{~s}$ as shown in Fig. 4. Then, the current $i_{N C C B}$ becomes zero and the fault current is commutated to the MB naturally once $T_{1}$ is turned off. 

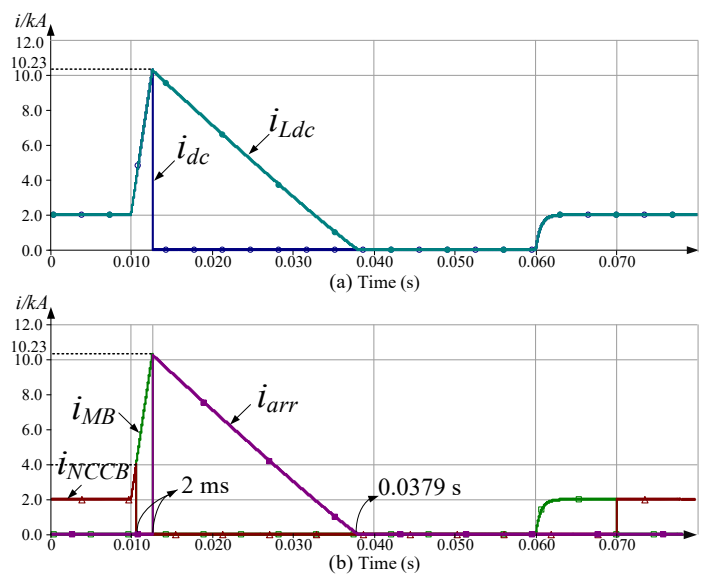

Fig. 4. Current waveforms during a pole-to-ground fault.

The $\mathrm{S}_{1}$ opens in $2 \mathrm{~ms}$, where the current $i_{M B}$ is increased to $10.23 \mathrm{kA}$. $\mathrm{S}_{1}$ opens at the time of $0.0126 \mathrm{~s}$. The fault current is blocked after turning off the $T_{2}$ in the MBs as shown in Fig. 4, where $i_{d c}$ drops to zero. From $0.0126 \mathrm{~s}$ to $0.0379 \mathrm{~s}$, the currents $i_{L d c}$ and $i_{\text {arr }}$ are reduced to zero gradually. In other words, the energy in $L_{d c}$ is gradually exhausted by the arrester. At $t=$ $0.0379 \mathrm{~s}$, the residual energy in $L_{d c}$ is totally consumed. Hereafter, the DC source is isolated from the faulted circuit once the two $\mathrm{S}_{2}$ are opened.

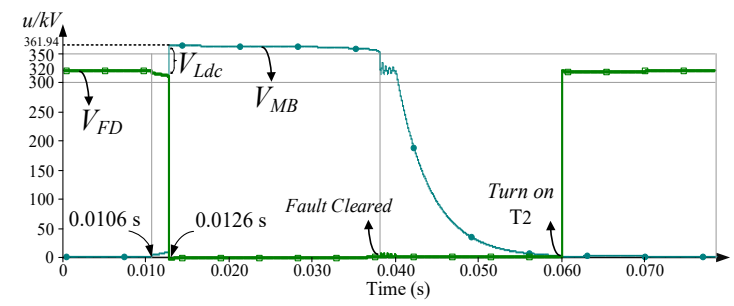

Fig. 5. Voltage waveforms during a pole-to-ground fault.

Fig. 5 shows the voltage waveforms during the fault blocking process. At $t=0.0126 \mathrm{~s}$, the voltage of freewheeling diodes group $V_{F D}$ drops to zero. $V_{M B}$ equals to the sum of DC voltage and the voltage of $L_{d c}(361.94 \mathrm{kV})$. After tripping $\mathrm{S}_{2}$, the energy stored in $C_{Q}$ will then be exhausted by $R_{Q}$ gradually.

The post-fault restoration begins at $t=0.05 \mathrm{~s}$. At the time of $0.06 \mathrm{~s}$, the $S_{2}$ is firstly closed. The $T_{2}$ will be turned on once $S_{2}$ is fully closed. Then, the currents $i_{L d c}$ and $i_{M B}$ are recovered to 2 $\mathrm{kA}$ as shown in Fig. 4. Meanwhile, $V_{F D}$ is almost recovered to DC voltage because of $R_{Q}<<R_{D}$. Note that the switching of $\mathrm{T}_{2}$ implements the ZVS and the switching of $S_{2}$ implements the zero current switching (ZCS). The triggering signal of $S_{1}$ is given at the time of $0.07 \mathrm{~s}$. As the load current is flowing through the MBs, $\mathrm{S}_{1}$ can be turned on under the ZCS as well. After two milliseconds, the load current will flow through NCCB by turning on $\mathrm{T}_{1}$.

\section{B. Pole-to-pole fault}

Compared with the pole-to-ground fault, the pole-to-pole fault is relative severe. The pole-to-pole fault protection can be implemented by installing two DB-HCBs in the positive and negative lines, as shown in Fig. 6. Note that the directions of the diodes in EBD and the IGBTs in MB of the two DB-HCBs are opposite due to the opposite current directions.
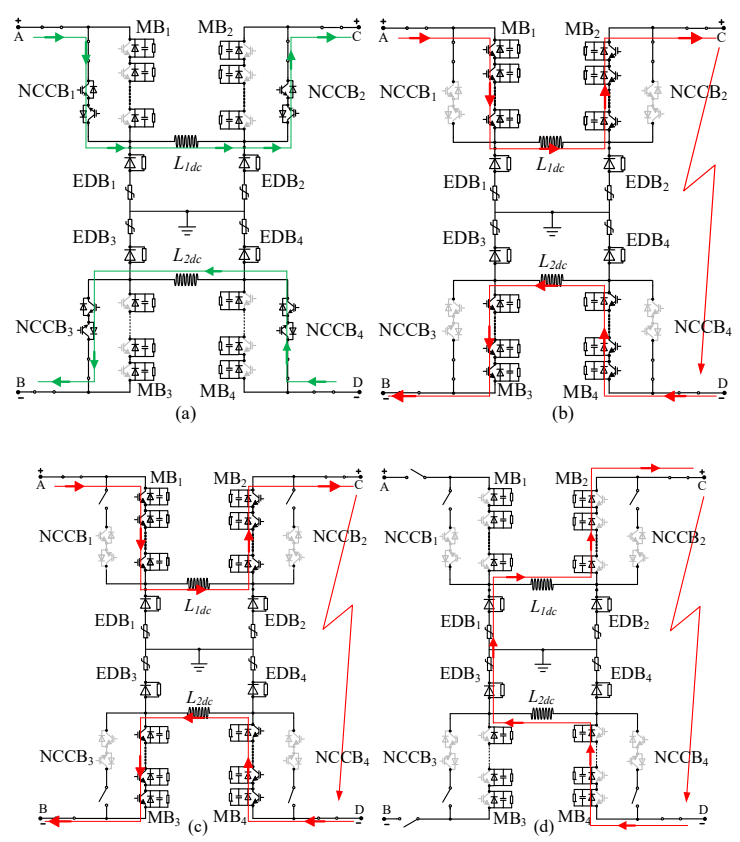

Fig. 6. Topology and interruption principles of protecting a pole-to-pole fault.

Fig. 6(a) shows the load current paths under system normal operation. Two arms are activated simultaneously once a poleto-pole fault is detected. The operational sequences of the poleto-pole protection are similar with the pole-to-ground fault protection, as shown in Fig. 6(b)-(d). The fault current will be exhausted by the surge arresters.

The pole-to-pole fault occurs at $t=0.01 \mathrm{~s}$. The fault current is increased to $4 \mathrm{kA}$ from $0.010 \mathrm{~s}$ to $0.0106 \mathrm{~s}$. At the time of $0.0106 \mathrm{~s}$, the fault current is commutated from the NCCB to the $\mathrm{MB}$, as shown in Fig. 6(b). After two milliseconds, as shown in Fig. 6(c), the UFDs in NCCBs are fully opened. Hereafter, the fault energy is exhausted by arresters by turning off MBs, as shown in Fig. 6(d).

Fig. 7 shows the currents in $\mathrm{MB}_{1}$ and $\mathrm{MB}_{4}$. It can be seen that there always exist the fault current in $\mathrm{MB}_{4}$ until the fault is fully eliminated. However, the fault current in $\mathrm{MB}_{1}$ is immediately interrupted after the IGBTs in $\mathrm{MB}_{1}$ are switched off. At the time of $0.0126 \mathrm{~s}$, the current flows through the $\mathrm{EDB}_{1}$ and $\mathrm{EDB}_{3}$ once the IGBTs in $\mathrm{MB}_{1}$ and $\mathrm{MB}_{4}$ are turned off. Fig. 8 shows the voltage transition stages of $\mathrm{MB}_{3}$ and the freewheeling diode group in $\mathrm{EBD}_{3}$. It can be seen that the fault is eliminated at the time of $0.0379 \mathrm{~s}$.

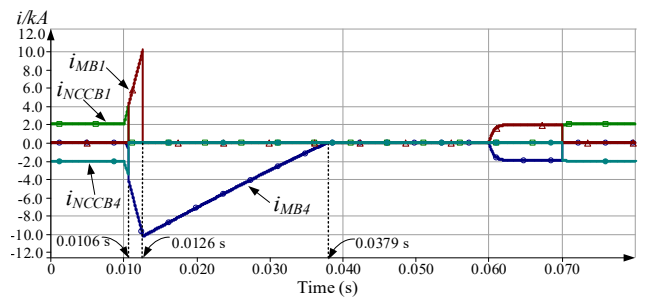

Fig. 7. Current waveforms during a pole-to-pole fault. 


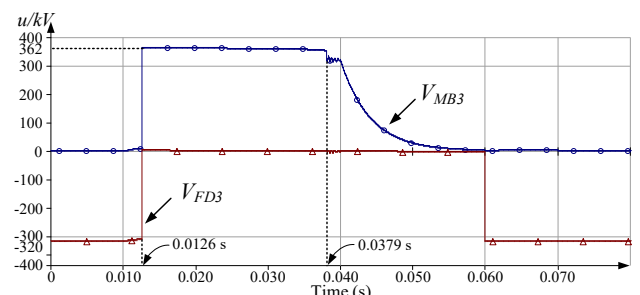

Fig. 8. Voltage waveforms during a pole-to-pole fault.

\section{CONCLUSIONS}

This paper proposes a dual-bridge hybrid DC circuit breaker for the protection of MTDC girds. The operation principle of the proposed DB-HCB for protecting both pole-to-ground and poleto-pole faults is presented. Simulation verification is performed in PSCAD/EMTDC to validate the effectiveness of the proposed DB-HCB. The studies show that the proposed DB-HCB can obviously reduce the capacity and volume of the surge arrester as well as maintain the energy dissipating capability. Therefore, the capital cost and volume of the proposed DB-HCB can be significantly reduced. Moreover, the DB-HCB is able to quickly isolate the converter from the faulted circuit in the help of the series-connected freewheeling diodes. ZVS can be implemented during the post-fault restoration processes and therefore, so that the operation safety and efficiency of the DB-HCB can be improved and result in a long lifetime. In addition, different $\mathrm{MBs}$ can be applied in the proposed DB-HCB with preserving its advantages, so as to increase the flexibility of the proposed topology.

\section{REFERENCES}

[1] J. M. Carrasco et al., "Power-Electronic Systems for the Grid Integration of Renewable Energy Sources: A Survey," in IEEE Transactions on Industrial Electronics, vol. 53, no. 4, pp. 1002-1016, June 2006.

2] G. Li, L. Zhang, T. Joseph, J. Liang and G. Yan, "Comparisons of MVAC and MVDC Systems in Dynamic Operation, Fault Protection and PostFault Restoration," in IEEE 45th Annual Conference of the IEEE Industrial Electronics Society (IECON 2019), Lisbon, Portugal, Oct. 2019.

[3] Z. Yuan, Y. Wang, Y. Yi, C. Wang, Y. Zhao and W. Wen, "Fast Linear Power Flow Algorithm for the Study of Steady-State Performance of DC Grid," in IEEE Transactions on Power Systems, vol. 34, no. 6, pp. 42404248, Nov. 2019.

[4] G. Li, J. Liang, C. E. Ugalde-Loo, P. Coventry and J. Rimez, "Dynamic interactions of DC and AC grids subject to DC faults," in 2016 IEEE 8th International Power Electronics and Motion Control Conference (IPEMC-ECCE Asia), Hefei, China, pp. 2627-2633.

[5] G. Li et al., "Power reversal strategies for hybrid LCC/MMC HVDC systems," in CSEE Journal of Power and Energy Systems, vol. 6, no. 1, pp. 203-212, March 2020.

[6] N. Flourentzou, V. G. Agelidis and G. D. Demetriades, "VSC-Based HVDC Power Transmission Systems: An Overview," in IEEE Transactions on Power Electronics, vol. 24, no. 3, pp. 592-602, March 2009.

[7] P. Bresesti, W. L. Kling, R. L. Hendriks and R. Vailati, "HVDC Connection of Offshore Wind Farms to the Transmission System," in IEEE Transactions on Energy Conversion, vol. 22, no. 1, pp. 37-43, March 2007.

[8] G. Li, J. Liang, F. Ma, C. E. Ugalde-Loo and H. Liang, "Analysis of Single-Phase-to-Ground Faults at the Valve-Side of HB-MMCs in
HVDC Systems," IEEE Trans. Ind. Electron., vol. 66, no. 3, pp. 24442453, March 2019.

[9] G. Li, W. Liu, T. Joseph, J. Liang and Z. Song, "Double-Thyristor-Based Protection for Valve-Side Single-Phase-to-Ground Faults in HB-MMCBased Bipolar HVDC Systems," in IEEE Transactions on Industrial Electronics, vol. 67, no. 7, pp. 5810-5815, July 2020.

[10] A. Hassanpoor, J. Häfner and B. Jacobson, "Technical assessment of load commutation switch in hybrid HVDC breaker," 2014 International Power Electronics Conference (IPEC-Hiroshima 2014 - ECCE ASIA), Hiroshima, 2014, pp. 3667-3673.

[11] A. H. Chang, B. R. Sennett, A. Avestruz, S. B. Leeb and J. L. Kirtley, "Analysis and Design of DC System Protection Using Z-Source Circuit Breaker," in IEEE Transactions on Power Electronics, vol. 31, no. 2, pp. 1036-1049, Feb. 2016

[12] Ji Shu, Shunliang Wang, Tianqi Liu, Ning Jiao, Yanbo Wang, A novel current-limiting circuit based on resistive-type SFCL for fault in DC power system, Microelectronics Reliability, Volumes 88-90, 2018, Pages 1201-1205, ISSN 0026-2714.

[13] Y. Wang, W. Wen, C. Zhang, Z. Chen and C. Wang, "Reactor Sizing Criterion for the Continuous Operation of Meshed HB-MMC-Based MTDC System Under DC Faults," in IEEE Transactions on Industry Applications, vol. 54, no. 5, pp. 5408-5416, Sept.-Oct. 2018.

[14] A. Shukla and G. D. Demetriades, "A Survey on Hybrid Circuit-Breaker Topologies," in IEEE Transactions on Power Delivery, vol. 30, no. 2, pp. 627-641, April 2015.

[15] W. Wen, Y. Huang, Y. Sun, J. Wu, M. Al-Dweikat and W. Liu, "Research on Current Commutation Measures for Hybrid DC Circuit Breakers," in IEEE Transactions on Power Delivery, vol. 31, no. 4, pp. 1456-1463, Aug. 2016.

[16] C. Peng, X. Song, A. Q. Huang and I. Husain, "A Medium-Voltage Hybrid DC Circuit Breaker-Part II: Ultrafast Mechanical Switch," in IEEE Journal of Emerging and Selected Topics in Power Electronics, vol. 5, no. 1, pp. 289-296, March 2017.

[17] J. H"afner and B. Jacobson, "Proactive hybrid HVDC breakers - A key innovation for reliable HVDC grid," in Proc. CIGRÉ Symp., Bologna, Italy, paper 264, Sep. 13-15, 2011

[18] P. Skarby and U. Steiger, "An Ultra-fast Disconnecting Switch for a Hybrid HVDC Breaker-a technical breakthrough," in CIGRE Canada Conference, paper 265, Alberta, Canada, Sep. 9-11, 2013.

[19] J. Häfner, B. Jacobson," Proactive Hybrid HVDC Breakers - A key innovation for reliable HVDC grids," Cigré Bologna, Paper 0264, 2011.

[20] A. Hassanpoor, J. Häfner and B. Jacobson, "Technical Assessment of Load Commutation Switch in Hybrid HVDC Breaker," in IEEE Transactions on Power Electronics, vol. 30, no. 10, pp. 5393-5400, Oct. 2015

[21] W. Zhou et al., "Development and test of a $200 \mathrm{kV}$ full-bridge based hybrid HVDC breaker," 2015 17th European Conference on Power Electronics and Applications (EPE'15 ECCE-Europe), Geneva, 2015, pp $1-7$.

[22] G. Tang, Z. He, H. Pang, X. Huang and X. Zhang, "Basic topology and key devices of the five-terminal DC grid," in CSEE Journal of Power and Energy Systems, vol. 1, no. 2, pp. 22-35, June 2015.

[23] Zhou Jie et al., "Research of DC circuit breaker applied on Zhoushan multi-terminal VSC-HVDC project," 2016 IEEE PES Asia-Pacific Power and Energy Engineering Conference (APPEEC), Xi'an, 2016, pp. 1636-1640

[24] Z. Lin, J. Qin, H. Ma, J. Liu, B. Yang and Y. Wang, "Design of 500kV Hybrid HVDC Circuit Breaker Control and Protection System," 2020 4th International Conference on HVDC (HVDC), 2020, pp. 134-139.

[25] W. Grieshaber, et al. "Development and test of a $120 \mathrm{kV}$ direct current circuit breaker," in CIGRÉ, Paris, France, 2014

[26] K. Sano and M. Takasaki, "A Surgeless Solid-State DC Circuit Breaker for Voltage-Source-Converter-Based HVDC Systems," in IEEE Transactions on Industry Applications, vol. 50, no. 4, pp. 2690-2699, July-Aug. 2014. 